\title{
$\mathrm{PVC}$ 바닥상재용 광경화형 내오염 코팅액의 \\ 제조 및 응용에 관한 연구
}

윤현정 ${ }^{1}$, 하진욱 ${ }^{*}$

${ }^{1}$ 순천향대학교 화학공학·환경공학과

\section{A study on the Manufacture and Application of UV-Cured Anti-stain Coating Compounds for PVC Tile}

\author{
Hyun-Jung Yoon ${ }^{1}$ and Jin-Wook Ha ${ }^{1^{*}}$ \\ ${ }^{1}$ Dept of Chemical \& Environmental Eng., College of Eng., Soonchunhyang Univ.
}

\begin{abstract}
요 약 본 연구는 건축자재로 널리 사용되는 PVC 바닥상재 표면을 오염성 및 정전기로부터 보호하기 위하여 기존 에 사용하는 광경화형 우레탄-아크릴 수지에 내오염/대전성을 향상시킨 광경화형 내오염 코팅액 개발에 관한 것이다. PVC 바닥상재용으로 사용되는 내오염성이 없는 우레탄-아크릴 수지에 4가 암모늄을 사용한 수용성 대전방지제와 아 크릴용 대전방지제, 폴리우리탄용 대전방지제를 수지의 양 대비 함량(wt\%) 5 20\%로 변화하여 첨가한 후 배합하여 수지의 내오염/대전성을 향상시킨 내오염 코팅액을 제조하였다. 제조한 내오염 코팅액은 코팅 층의 두께조절이 가능 한 코팅(Bar-coating)을 사용하여 PVC 바닥상재에 코팅 한 후 내오염성, 대전성, 부착력, 코팅두께 등의 코팅 층 표면 물성을 평가하였다. 연구결과, 수지에 수용성대전방지제 $15 \%$ 를 혼합하여 제조한 코팅액을 Bar-coater No.12로 코팅한 코팅표면이 전기저항 $\left(3.24 \times 10^{9} \Omega / \mathrm{cm}^{2}\right)$, 내오염도(매직 Test, 먼지부착 Test) 및 부착력 $(100 \%)$ 모두 가장 좋은 물성을 보 였다. 전반적으로 함량이 많을수록 전기저항과 오염도에서 우수한 것으로 나타났다. 그러나 대전방지제가 과량으로 들어간 경우 migration 현상이 보이는 것을 알 수 있었다.
\end{abstract}

\begin{abstract}
This study is on development of UV-cured anti-stain coating compounds which have more improved anti-stain function to prevent a surface of PVC tile from stain. To make an anti-stain coating composition, water soluble antistatic agent made from ammonium(IV) salt, antistatic agents for acrylic and polyurethane were used. Their contents varied from 5 to $20 \mathrm{wt} \%$ against quantities of resin in coating composition. After coating PVC tiles using bar-coating method that can adjust a thickness, we estimated surface properties of coated layer such as anti-stain, electric resistance, adhesive power, thickness of coating, and so on. Results showed that a coating composition added $15 \mathrm{wt} \%$ of water soluble antistatic agent and coated with No.12 bar-coater had the optimum surface property in electric resistance $\left(3.24 \times 10^{9} \Omega / \mathrm{cm}^{2}\right)$, anti-stain(ink Test, Dust Test) and adhesive power. We could also find electric resistance and anti-stain effect were improved as antistatic agent content increased. However, excessive addition of antistatic agents(over $20 \mathrm{wt} \%$ ) caused the migration.
\end{abstract}

Key Words : UV-Cure, PVC Tile, Anti-stain, Electrostatic

\section{1. 서론}

일반적인 플라스틱 제품은 부도체로서 마찰에 의한 정 전기가 쉽게 발생하며 이러한 플라스틱의 정전기 장해를 극복하기 위한 방법은 여러 분야에서 제안되고 있다[1,2].
정전기는 산업현장에서 크고 작은 장해를 일으키는 원 인이 되는데, 정전기로 인하여 화재, 폭발 재해가 발생하 며, 반도체산업 및 전자산업이 발전함에 따라 반도체 부 품 등의 파괴 또는 성능저하를 초래한다. 이로 인해 표면 과 계면에 특이한 활성능을 나타내기 위한 대전방지제의

*교신저자 : 하진욱(chejwh@sch.ac.kr) 
많은 연구가 진행되고 있다[6,7].

대전방지제는 건조를 빠르게 진행시키기 위하여 유기 용제가 주로 사용되고 있다. 그러나 유기용제의 사용은 코 팅공정에서 휘발성 유기물질(Volatile organic compound, $\mathrm{VOC})$ 을 배출하게 되며 이로 인하여 환경오염을 유발하 게 된다. 최근 환경문제가 대두되면서 용제형 도료 대신 수계 도료가 선호되고 있으며 환경친화성 뿐만 아니라 건축 재료의 보호 및 외관의 향상에 초점을 두는 기능성 도료의 연구개발이 활발히 진행되고 있다. 이러한 기능성 중 미관과 직접 연관된 것이 내오염성이다. 건축용 도막 에 내오염성을 부여하여 오염물이 접착 또는 부착되지 않도록 하는 방법뿐만 아니라 접착된 오염물이 쉽게 제 거되도록 하는 방법으로 어린아이가 있는 집에서 낙서나 이물질을 쉽게 지울 수 있어 다양한 소비자들이 선호하 는 제품으로 손꼽히고 있다[3-5].

본 연구에서는 기존 $\mathrm{PVC}$ 상재에 사용되는 용제형 광 경화 도료를 대체하고, 바닥재로 많이 사용되는 $\mathrm{PVC}$ Tile의 오염을 방지하기 위한 내오염 및 대전 기능을 개 선할 수 있는 환경친화적이며 내오염(Anti-stain) 기능을 지닌 광경화형 수성도료에 대한 연구를 진행 하였다.

\section{2. 실험}

\section{1. 코팅액 제조방법 및 코팅조건}

PVC Tile의 내오염성을 증가시키기 위해 일반 UV코 팅액(국산, (주)유진텍21)에 수용성 대전방지제 UJAS2006(국산, (주)유진텍21), UV경화 아크릴용 대전방지 제 JISTA $411 \mathrm{UV}$ (국산, 중일유화주식회사), 폴리우레탄 용 대전방지제 JISTA 2000NT(국산, 중일유화주식회사) 를 수지의 양 대비 $5 \%, 10 \%, 15 \%, 20 \%$ 함량으로 조절하 여 첨가하였다. 일반 $\mathrm{UV}$ 코팅액의 조성과 대전방지제의 특성은 표1, 표2에 나타내었다.

$\mathrm{UV}$ 코팅액과 대전방지제를 배합하기 위해 고속 배합 기를 사용하여 $1000 \mathrm{rpm}$ 으로 30 분간 배합하여 내오염 코 팅액을 제조하였다. 제조한 내오염 코팅액을 $10 \mathrm{~cm} \times 10 \mathrm{~cm}$ 크기의 PVC Tile에 두께가 다른 두 가지 Bar-coater (No.7, No.12)를 사용하여 코팅하였다. 코팅된 PVC Tile 은 UV경화기(국산, Lichtzen)로 자외선 조사량 $1.5 \mathrm{kw}$, 경 화속도 $1.5 \mathrm{~m} / \mathrm{min}$, 경화횟수 1 회로 동일한 조건에서 경화 하였다. 코팅액 제조방법 및 코팅 조건은 그림 1 과 같다.
[표 1] UV 코팅액의 조성

\begin{tabular}{|c|c|}
\hline 성 분 & 함 량 \\
\hline 광 개 시 제 & 4.9 \\
\hline 모 노 머 & 59.5 \\
\hline 올 리 고 머 & 35 \\
\hline 첨 가 제 & 0.6 \\
\hline 합 계 & 100 \\
\hline
\end{tabular}

[표 2] 대전방지제의 특성

\begin{tabular}{|c|c|c|c|}
\hline $\begin{array}{c}\text { 대전 } \\
\text { 방지제 }\end{array}$ & $\begin{array}{c}\text { 수용성 } \\
\text { 대전방지제 }\end{array}$ & $\begin{array}{c}\text { UV경화아크릴 } \\
\text { 용대전방지제 }\end{array}$ & $\begin{array}{c}\text { 폴리우레탄용 } \\
\text { 대전방지제 }\end{array}$ \\
\hline 상품명 & $\begin{array}{c}\mathrm{UJ}-\mathrm{AS} \\
2006\end{array}$ & JISTA 411UV & $\begin{array}{c}\text { JISTA } \\
2000 N T\end{array}$ \\
\hline 주성분 & $\begin{array}{c}4 \text { 급암모늄 } \\
\text { 술폰산 } \\
\text { 화합물 }\end{array}$ & $\begin{array}{c}\text { 전도성고분자 } \\
\text { 및 } \\
\text { Polysiloxane }\end{array}$ & $\begin{array}{c}\text { 전도성고분자 } \\
\text { 및 비이온계 } \\
\text { 계면활성제 }\end{array}$ \\
\hline $\begin{array}{c}\text { 비중 } \\
\left(25^{\circ} \mathrm{C}\right)\end{array}$ & 1.3 & $1.07 \pm 0.01$ & 1.45 \\
\hline $\mathrm{pH}$ & $7.0 \pm 1.0$ & $7.0 \pm 1.0$ & $7.0 \sim 8.0$ \\
\hline 제조사 & $\begin{array}{c}\text { (주)유진텍 } \\
21\end{array}$ & $\begin{array}{c}\text { 중일유화 } \\
\text { 주식회사 }\end{array}$ & $\begin{array}{c}\text { 중일유화 } \\
\text { 주식회사 }\end{array}$ \\
\hline
\end{tabular}

$\mathrm{UV}$ 코팅액 + 대전방지제 $5 \%, 10 \%, 15 \%, 20 \%$

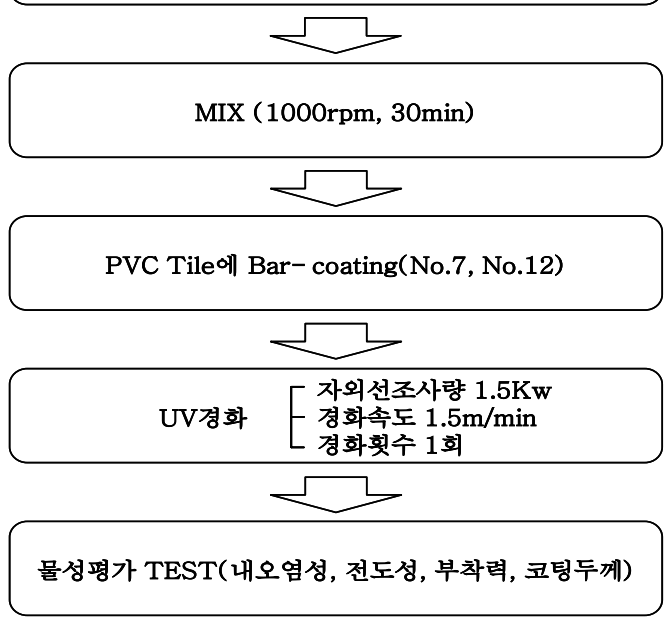

[그림 1] 코팅액 제조 및 UV경화 코팅조건

\section{2. 코팅 층 물성 평가}

코팅된 PVC Tile의 전기저항성 평가는 절연저항측정 기(일본, HIOKI사)로 JIS K6911에 기준하여 PVC Tile의 표면의 표면 저항 및 체적 저항 정도에 따라 평가하였다. 전기저항성 측정은 습도 $35 \sim 45 \%$ 내에서 측정하였다. 본 연구의 코팅층 전기저항성 목표치는 $10^{9} \sim 10^{10} \Omega / \mathrm{cm}^{2}$ 이다. 


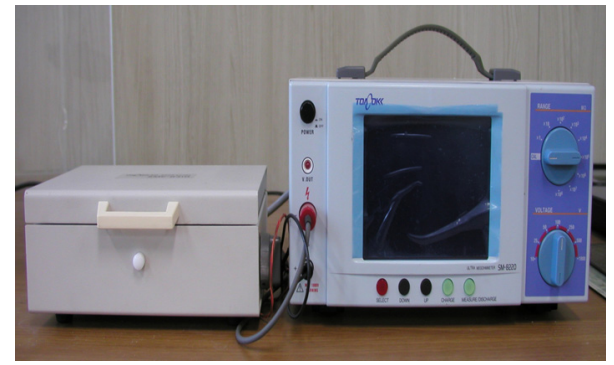

[그림 2] 전기저항성 평가방법

내오염성 평가 중 매직 Test는 Tile 표면에 유성매직으로 표시 후 Ethanol로 제거하였을 때 코팅층 표면에 남아있는 유성 매직 표시의 유·무(Pass/Fail) 관찰로 평가하였다.

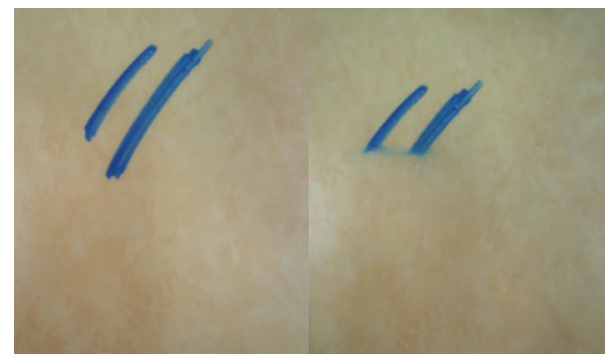

[그림 3] 매직 테스트 평가방법

내오염성 평가 중 먼지부착 Test는 입자 밀도가 낮은 담뱃재를 이용하여 Tile 표면에 정전기를 발생시킨 후 담 뱃재의 부착 유·무(Pass/Fail)로 평가 하였다.

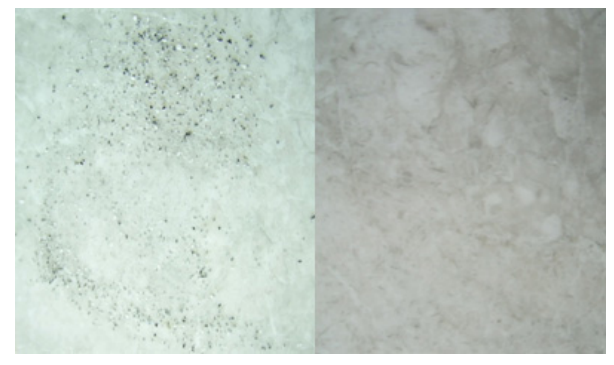

[그림 4] 먼지부착 테스트 평가방법

코팅층의 두께 측정은 초음파 multi-layer 코팅 두께 측정기(미국, Defelsko, positector $\left.{ }^{\circledR} 100\right)$ 로 5 회 측정 후 평 균값으로 평가하였다.

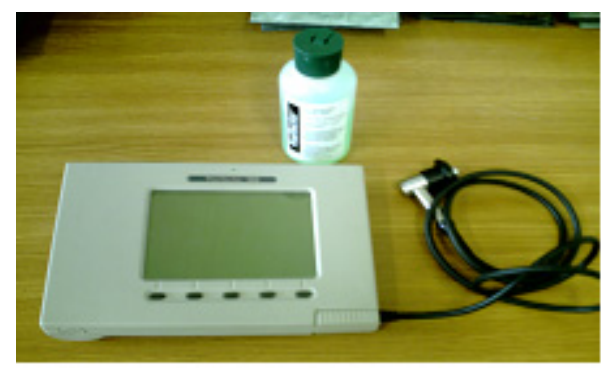

[그림 5] 코팅두께 테스트 평가방법

부착력평가는 ASTM D 3359에 근거하여 코팅 표면에 $1 \mathrm{~mm}$ 간격으로 십자형의 칼집을 내어 100 개의 정방형을 만들고 $3 \mathrm{M}$ 테이프를 잘 밀착시켜 일정한 힘으로 수회 떼 어내어 코팅 층과 기재와의 밀착정도를 관찰하였다. 코팅 의 박리등급에 따른 자세한 기준은 그림 6 과 같다.

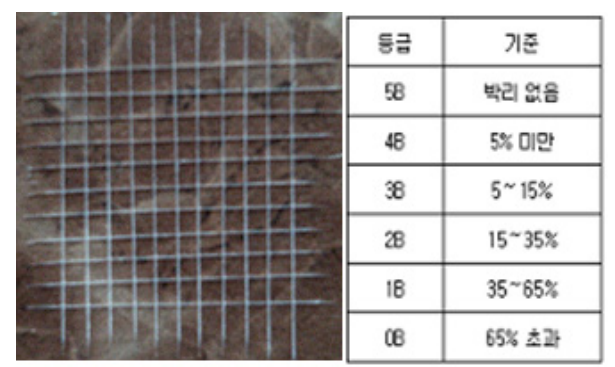

[그림 6] 부착력 테스트 평가방법

\section{3. 결과 및 고찰}

[표 3] 대전방지제 종류와 함량에 따른 코팅액 분류

\begin{tabular}{|c|c|c|c|}
\hline & 분 류 & 품 명 & 함 량 \\
\hline$A-1$ & \multirow{4}{*}{$\begin{array}{c}\text { 수용성 대전방지제 } \\
\text { (4가 암모늄) }\end{array}$} & \multirow{4}{*}{$\begin{array}{c}\text { UJ } \\
\text { AS2006 }\end{array}$} & $5 \%$ \\
\hline$A-2$ & & & $10 \%$ \\
\hline$A-3$ & & & $15 \%$ \\
\hline$A-4$ & & & $20 \%$ \\
\hline$B-1$ & \multirow{4}{*}{$\begin{array}{l}\text { UV경화 아크릴용 } \\
\text { 대전방지제 } \\
\text { (Polysiloxane) }\end{array}$} & \multirow{4}{*}{$\begin{array}{l}\text { JISTA } \\
411 U V\end{array}$} & $5 \%$ \\
\hline$B-2$ & & & $10 \%$ \\
\hline$B-3$ & & & $15 \%$ \\
\hline$B-4$ & & & $20 \%$ \\
\hline C-1 & \multirow{4}{*}{$\begin{array}{c}\text { 폴리우레탄용 } \\
\text { 대전방지제 } \\
\text { (Conductive Polymer) }\end{array}$} & \multirow{4}{*}{$\begin{array}{l}\text { JISTA } \\
\text { 2000NT }\end{array}$} & $5 \%$ \\
\hline C-2 & & & $10 \%$ \\
\hline$C-3$ & & & $15 \%$ \\
\hline C-4 & & & $20 \%$ \\
\hline
\end{tabular}

PVC Tile의 알맞은 내오염 코팅의 조건을 찾기 위하 여 대전방지제의 함량을 조절하여 내오염 코팅액을 제조 
하였다.

시료는 대전방지제의 종류와 함량에 따라 각각 세 가 지로 분류하여 표기하였고, 본 연구에 사용된 대전방지제 종류와 첨가된 함량은 표 3 에 나타내었다.

\subsection{UJ-AS2006 대전방지제의 코팅층 물성 평가}

수용성 대전방지제(4가 암모늄) UJ-AS2006으로 제조 한 내오염 코팅액 A-1, 2, 3, 4를 PVC Tile에 코팅하여 평 가한 물성결과는 표 4와 같다.

내오염성 Test 결과 전기저항성은 $10^{9} \sim 10^{10} \Omega / \mathrm{cm}^{2}$ 으로 본 연구의 목표치에 적합한 양호한 결과가 나왔다. 매직 Test와 먼지부착 Test는 A-1, 2 코팅층에서는 매직과 담 뱃재가 남는 좋지 못한 결과가 나왔으나 A-3, 4에서는 모 두 양호하였다. 그러나 A-4의 경우 과량의 대전방지제 첨 가에 의한 migration현상이 일어나 코팅층 물성이 저하되 었다.
코팅 두께에 따른 코팅층 물성은 차이를 보이지 않았 다. 부착력은 ASTM D 3359 부착력 평가에 따라 최상등 급인 5B로 모두 매우 우수하였고, 코팅두께는 Bar-coater No.7이 $16 \mu \mathrm{m}$ 이고, No.12가 $27.43 \mu \mathrm{m}$ 이므로 비교적 적절하 게 나왔다. UJ-AS2006 대전방지제 코팅의 결과 함량이 많을수록 우수한 것으로 나타났다.

\subsection{JISTA 411UV 대전방지제의 코팅층 물성 평가}

UV경화 아크릴용 대전방지제(Polysiloxane) JISTA 411UV로 제조한 내오염 코팅액 B-1, 2, 3, 4를 PVC Tile 에 코팅하여 평가한 결과는 표 5 와 같다.

내오염성 Test 결과 전기저항성은 $\mathrm{B}-2,3,4$ 의 경우 $10^{9} \sim 10^{10} \Omega / \mathrm{cm}^{2}$ 으로 양호하게 나왔으나 B-1의 경우 $10^{11} \Omega /$ $\mathrm{cm}^{2}$ 으로 전기저항성이 높게 측정되는 것을 알 수 있었다. 매직 Test와 먼지부착 Test에서는 UJ-AS2006을 첨가한 코팅층의 경우와는 다르게 B-3에서 코팅두께가 두꺼울수

[표 4] UJ-AS2006 대전방지제의 코팅층 물성평가

\begin{tabular}{|c|c|c|c|c|c|c|c|c|c|c|}
\hline \multirow{2}{*}{} & \multicolumn{4}{|c|}{ No.7 } & \multicolumn{5}{c|}{ No.12 } \\
\cline { 2 - 11 } & 전기저항 & \multicolumn{2}{|c}{ 내오염도 } & 부착력 & 코팅두께 & 전기저항 & \multicolumn{2}{|c|}{ 내오염도 } & 부착력 & 코팅두께 \\
\cline { 2 - 12 } & $\Omega / \mathrm{cm}^{2}$ & 매직Test & 먼지Test & cross-cut & 초음파 & $\Omega / \mathrm{cm}^{2}$ & 매직Test & 먼지Test & cross-cut & 초음파 \\
\hline $\mathrm{A}-1$ & $5.37 \times 10^{10}$ & $\mathrm{~F}$ & $\mathrm{~F}$ & $5 \mathrm{~B}$ & $19.0 \mu \mathrm{m}$ & $3.46 \times 10^{10}$ & $\mathrm{~F}$ & $\mathrm{~F}$ & $5 \mathrm{~B}$ & $26.2 \mu \mathrm{m}$ \\
\hline $\mathrm{A}-2$ & $4.15 \times 10^{10}$ & $\mathrm{~F}$ & $\mathrm{~F}$ & $5 \mathrm{~B}$ & $18.6 \mu \mathrm{m}$ & $2.40 \times 10^{10}$ & $\mathrm{~F}$ & $\mathrm{~F}$ & $5 \mathrm{~B}$ & $27.6 \mu \mathrm{m}$ \\
\hline $\mathrm{A}-3$ & $6.12 \times 10^{9}$ & $\mathrm{P}$ & $\mathrm{P}$ & $5 \mathrm{~B}$ & $19.0 \mu \mathrm{m}$ & $3.24 \times 10^{9}$ & $\mathrm{P}$ & $\mathrm{P}$ & $5 \mathrm{~B}$ & $27.7 \mu \mathrm{m}$ \\
\hline $\mathrm{A}-4$ & $4.43 \times 10^{9}$ & $\mathrm{P}$ & $\mathrm{P}$ & $5 \mathrm{~B}$ & $19.3 \mu \mathrm{m}$ & $1.43 \times 10^{9}$ & $\mathrm{P}$ & $\mathrm{P}$ & $5 \mathrm{~B}$ & $27.1 \mu \mathrm{m}$ \\
\hline
\end{tabular}

[표 5] JISTA 411UV 대전방지제의 코팅층 물성평가

\begin{tabular}{|c|c|c|c|c|c|c|c|c|c|c|}
\hline \multirow{2}{*}{} & \multicolumn{4}{|c|}{ No.7 } & \multicolumn{5}{c|}{ No.12 } \\
\cline { 2 - 11 } & 전기저항 & \multicolumn{2}{|c}{ 내오염도 } & 부착력 & 코팅두께 & 전기저항 & \multicolumn{2}{|c|}{ 내오염도 } & 부착력 & 코팅두께 \\
\cline { 2 - 12 } & $\Omega / \mathrm{cm}^{2}$ & 매직Test & 먼지Test & cross-cut & 초음파 & $\Omega / \mathrm{cm}^{2}$ & 매직Test & 먼지Test & cross-cut & 초음파 \\
\hline $\mathrm{B}-1$ & $4.36 \times 10^{11}$ & $\mathrm{~F}$ & $\mathrm{~F}$ & $5 \mathrm{~B}$ & $14.3 \mu \mathrm{m}$ & $2.57 \times 10^{11}$ & $\mathrm{~F}$ & $\mathrm{~F}$ & $5 \mathrm{~B}$ & $26.0 \mu \mathrm{m}$ \\
\hline $\mathrm{B}-2$ & $7.10 \times 10^{10}$ & $\mathrm{~F}$ & $\mathrm{~F}$ & $5 \mathrm{~B}$ & $18.3 \mu \mathrm{m}$ & $5.17 \times 10^{10}$ & $\mathrm{~F}$ & $\mathrm{~F}$ & $5 \mathrm{~B}$ & $27.0 \mu \mathrm{m}$ \\
\hline $\mathrm{B}-3$ & $2.27 \times 10^{10}$ & $\mathrm{~F}$ & $\mathrm{~F}$ & $5 \mathrm{~B}$ & $16.3 \mu \mathrm{m}$ & $2.04 \times 10^{10}$ & $\mathrm{P}$ & $\mathrm{P}$ & $5 \mathrm{~B}$ & $26.2 \mu \mathrm{m}$ \\
\hline $\mathrm{B}-4$ & $1.00 \times 10^{10}$ & $\mathrm{P}$ & $\mathrm{P}$ & $5 \mathrm{~B}$ & $17.8 \mu \mathrm{m}$ & $7.05 \times 10^{9}$ & $\mathrm{P}$ & $\mathrm{P}$ & $5 \mathrm{~B}$ & $26.8 \mu \mathrm{m}$ \\
\hline
\end{tabular}

[표 6] JISTA 2000NT 대전방지제의 코팅층 물성평가

\begin{tabular}{|c|c|c|c|c|c|c|c|c|c|c|}
\hline \multirow{3}{*}{} & \multicolumn{4}{|c|}{ No.7 } & \multicolumn{5}{c|}{ No.12 } \\
\cline { 2 - 11 } & 전기저항 & \multicolumn{2}{|c}{ 내오염도 } & 부착력 & 코팅두께 & 전기저항 & \multicolumn{2}{|c|}{ 내오염도 } & 부착력 & 코팅두께 \\
\cline { 2 - 11 }$y$ & $\Omega / \mathrm{cm}^{2}$ & 매직Test & 먼지부착 & cross-cut & 초음파 & $\Omega / \mathrm{cm}^{2}$ & 매직Test & 먼지부착 & cross-cut & 초음파 \\
\hline $\mathrm{C}-1$ & $6.26 \times 10^{11}$ & $\mathrm{~F}$ & $\mathrm{~F}$ & $5 \mathrm{~B}$ & $16.3 \mu \mathrm{m}$ & $4.90 \times 10^{11}$ & $\mathrm{~F}$ & $\mathrm{~F}$ & $5 \mathrm{~B}$ & $28.3 \mu \mathrm{m}$ \\
\hline $\mathrm{C}-2$ & $4.40 \times 10^{11}$ & $\mathrm{~F}$ & $\mathrm{~F}$ & $5 \mathrm{~B}$ & $16.2 \mu \mathrm{m}$ & $1.67 \times 10^{11}$ & $\mathrm{~F}$ & $\mathrm{~F}$ & $5 \mathrm{~B}$ & $27.0 \mu \mathrm{m}$ \\
\hline $\mathrm{C}-3$ & $1.89 \times 10^{11}$ & $\mathrm{P}$ & $\mathrm{P}$ & $5 \mathrm{~B}$ & $18.7 \mu \mathrm{m}$ & $1.08 \times 10^{11}$ & $\mathrm{P}$ & $\mathrm{P}$ & $5 \mathrm{~B}$ & $27.7 \mu \mathrm{m}$ \\
\hline $\mathrm{C}-4$ & $6.22 \times 10^{10}$ & $\mathrm{P}$ & $\mathrm{P}$ & $5 \mathrm{~B}$ & $18.5 \mu \mathrm{m}$ & $3.54 \times 10^{10}$ & $\mathrm{P}$ & $\mathrm{P}$ & $5 \mathrm{~B}$ & $27.1 \mu \mathrm{m}$ \\
\hline
\end{tabular}


록 유성매직과 담뱃재가 남지 않은 결과가 나왔고 B-4 코팅층은 역시 좋은 결과를 얻을 수 있었다. 부착력은 $\mathrm{UJ}-\mathrm{AS} 2006$ 과 마찬가지로 $5 \mathrm{~B}$ 인 최상등급이 나왔으며 코 팅두께도 적절하게 나왔다. A-4와 마찬가지로 B-4에서는 대전방지제 과량의 첨가로 인해 migration 현상이 일어나 코팅층 물성이 저하되었다.

\subsection{JISTA $2000 N T$ 대전방지제의 코팅층 물 성평가}

폴리우레탄용 대전방지제(Conductive Polymer) JISTA 2000NT로 제조한 내오염 코팅액 C-1, 2, 3, 4를 PVC Tile 에 코팅하여 평가한 결과는 표 6과 같다.

내오염성 Test 결과 전기저항성은 $10^{10} \sim 10^{11} \Omega / \mathrm{cm}^{2}$ 으로 다른 대전방지제 첨가 코팅액보다 높은 측정값을 나타냈 다. 매직 Test와 먼지부착 Test는 UJ-AS2006과 마찬가지 로 C-3, 4에서 매직과 담뱃재가 남지 않아 양호한 결과를 얻었다. 시료의 부착력 Test는 앞의 두 실험 결과와 같이 박리현상이 없는 최상등급인 $5 \mathrm{~B}$ 로 매우 우수하였으며, 코팅 두께 역시 적절하게 나왔다. A-4, B-4와 마찬가지로 $\mathrm{C}-4$ 에서는 대전방지제 과량의 첨가로 인해 migration 현 상이 일어났다.

\section{4. 결론}

본 연구에서는 기존의 우레탄-아크릴 수지에 내오염성 을 증가시키기 위하여 3가지 종류의 대전방지제(UJAS2006, JISTA 411UV, JISTA 2000NT)를 첨가하여 $\mathrm{PVC}$ Tile에 코팅한 후 그 물성을 관찰한 결과, 다음과 같 은 결과가 나왔다.

1. 수지에 수용성 대전방지제(UJ-AS2006)를 혼합하여 제조한 코팅액의 경우 전기저항성 $10^{9} \sim 10^{10} \Omega / \mathrm{cm}^{2}$, 아크릴 용 대전방지제(JISTA 411UV)를 혼합하여 제조한 코팅액 의 전기저항성은 $10^{9} \sim 10^{11} \Omega / \mathrm{cm}^{2}$, 폴리우레탄용 대전방지 제(JISTA 2000NT)를 혼합한 코팅액의 전기저항성은 $10^{10} \sim 10^{11} \Omega / \mathrm{cm}^{2}$ 으로 측정되었다.

2. 매직 Test와 먼지부착 Test는 함량이 증가할수록 코 팅층 표면에 남아있는 매직과 담뱃재의 양이 적어지는 결과를 얻었으며 대전방지제 $20 \%$ 이상 첨가 시 migration 현상으로 코팅층 물성에 저하를 일으켰다.

3. 세 가지 종류의 대전방지제의 부착력은 $100 \%$ 로 모 든 코팅층에서 좋은 결과를 나타냈다.

4. 우레탄-아크릴 수지에 수용성 대전방지제(UJ-
$\mathrm{AS} 2006)$ 를 $15 \%$ 혼합하여 제조한 코팅액을 Bar-coater $\mathrm{No} .12(27.43 \mu \mathrm{m})$ 로 코팅한 PVC 바닥상재가 전기저항성 $3.24 \times 10^{9} \Omega / \mathrm{cm}^{2}$, 매직오염도와 먼지부착 Test 양호, 부착력 $100 \%$ 로 가장 좋은 물성을 보였다.

\section{참고문헌}

[1] 이도현, 하진욱, “복합기능(대전방지/미끄럼방지)을 보 유한 열경화형 코팅제의 합성 및 그 응용에 관한 연 구”, Applied Chemistry, Vol. 5, No. 2, pp. 332 335, 2001.

[2] 이도현, 하진욱 “수용성 대전방지제의 합성 및 이를 이용한 PVC 바닥재 코팅” 산학기술성공학회 춘계학 술대회 발표논문, pp. 73 75, 2001.

[3] 하진욱, "환경친화적·반영구적 수용성 대전방지 코팅 액 개발", Applied Chemistry, Vol 6, No. 1, pp. 480 483, 2002.

[4] 이상민, 김준우, 신길재, 박상권, 임종주, 김병식, 홍 승민, 이현기, 박종명, "Water Vapor 투과도, 흡수성, 내오염성에 미치는 라텍스 필름 조성의 영향”, Applied Chemistry, Vol. 4, No. 1, pp. 49 52, 2000.

[5] 김의식, 민일홍, "대전방지 UV 경화형 Coating제의 제조와 응용" Journal of Industrial Science and Technology Institute, Vol. 18, No. 2, pp. 1 7, 2004.

[6] 김승진, 김한구, 근장현, 박흥수, “수용성 폴리아민 내구성 대전방지제의 합성과 그의 특성화”, Journal of Korean Ind. \& Eng. Chemistry, Vol. 5, No. 3, pp. 466 477, 1994.

[7] 장영민, 정재희, 이관형, 차영식, 정춘기, 이덕출, "대 전방지처리된 물질의 정전기 대전특성에 관한 연구”, Journal of KIIS, Vol. 10, No. 1, pp. 20 27, 1995.

\section{윤 현 정(Hyun-Jung Yoon)}

[준회원]

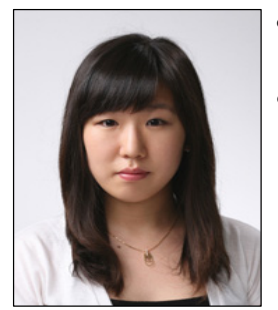

- 2009년 2월 : 순천향대학교 환경 공학과 (공학사)

- 2009년 3월 현재 : 순천향대 학교 화학공학-환경공학과 석사 과정

<관심분야>

광촉매, 기능성 코팅, 대기 - 수질 정화, 친환경소재, 대체에너지 분야 
하 진 욱(Jin-Wook Ha)

[종신회원]

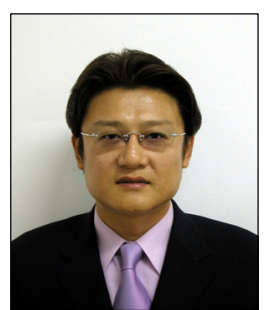

- 1986년 2월 : 연세대학교 화학공 학과 (공학사)

- 1990년 8월 : (미) Univ. of Illinois 화학공학과 (공학석사)

- 1993년 5월 : (미) Univ. of Illinois 화학공학과 (공학박사)

- 1995년 3월 현재 : 순천향대

학교 에너지환경공학과 교수

<관심분야>

광촉매, 기능성 코팅, 대기 - 수질 정화, 친환경소재, 대체에너지 분야 